\title{
What causes glacial-interglacial cycles?
}

\section{Louvain-la-Neuve, Belgium, 26-29 May 2008}

\section{Michel Crucifix}

Georges Lemaître Institute of Astronomy and Geophysics, Catholic University of Louvain, Louvain-la-Neuve, Belgium; michel.crucifix@uclouvain.be

This question has been inspiring André Berger's research for over 35 years. André Berger became a key character in the world of past and future climate modeling with his 1978 publication on frequencies, phase and amplitudes of Earth's orbital elements over the Quaternary. This publication contained the famous 19, 23, 41, 100 and 412 kyr periods, known as the "Milankovitch" frequencies. Since then, he and his team in Louvain-la-Neuve, Belgium have continued to deliver world-leading research on the astronomical theory of paleoclimate. On the occasion of his recent retirement, a symposium entitled "Climate change: From the geologic past to the uncertain future" was organized to celebrate his life's work.

The first day of the meeting was devoted to key components of climate, with lectures on the carbon cycle (F. Joos), landsurface feedbacks (M. Claussen), ice-sheets (P. Huybrechts) and ocean sediment dynamics (G. Munhoven).

Presentations then covered the intricacies of the connections between these different components on geological timescales. For example, M. Sarnthein examined the consequences of the closure of Panama Seaway on the atmosphere, salinity in the Arctic Ocean and large-scale glaciation of the northern hemisphere, while Z. Guo discussed the possible effects of Tibetan plateau uplift on regional atmospheric circulation.

The meeting was also rich in thoughtprovoking ideas, such as E. Wolff's suggestion that Antarctic "warm events" (characteristic of glaciations) were in fact aborted terminations. The younger generation was also well represented. P. Langebroeck gave an excellent presentation on the response of the Antarctic Ice Sheet to orbital variations and atmospheric $\mathrm{CO}_{2}$ in the Middle Miocene, and Q. Yin suggested that moderate amounts of ice in Eurasia may have strengthened the East Asian summer monsoon during pre-stage-11 interglacials. P. Köhler proposed a "Southern Ocean decoupling hypothesis" for the mid-Pleistocene transition, while A. Antico covered the modulation of the astronomical forcing by sea-ice during the Early Pleistocene.

Some presentations also suggested that the strength of certain climate feedbacks might be less than currently believed. F. Joos, for example, showed simulations suggesting that changes in the carbon cycle might not be as sensitive to the strength

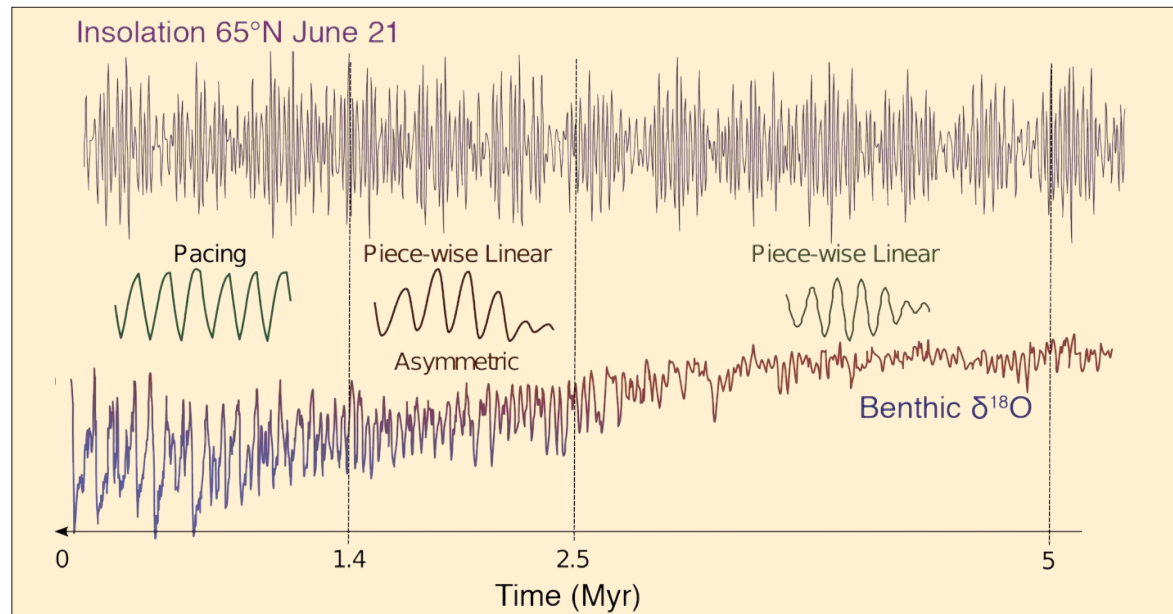

Figure 1: Lorraine Lisiecki discussed the 'LR04'5.3 Myr-long record obtained by lining up 57 records of benthic foraminifera $\delta^{18} \mathrm{O}$ (Lisiecki and Raymo, 2005). She showed evidence for 2 significant transitions in the climate response to the orbital forcing: one around 2.5 Myr ago, when the saw-toothed shape characteristic of glacial cycles first appeared, and one around 1.4 Myr when the response to obliquity shifted from linear response to non-linear pacing. Orbital forcing is represented here by summer solstice insolation obtained from the La04 model (Laskar et al., 2004). More details are available in Lisiecki and Raymo, 2007. Figure provided by L. Lisiecki.

and position of southern westerlies as previously thought. In fact, the links between southern temperature and $\mathrm{CO}_{2}$, so obvious in the ice-core records shown by D. Raynaud, are not easy to elucidate.

It was also evident that we still have much to learn about the effects of orbital forcing on climate. J.C. Duplessy presented a simulation based on data and model experiments, according to which high summer insolation in the northern hemisphere leads to an increase in southern ocean temperature, with potential effects on the West Antarctic Ice Sheet. P. Huybers presented the idea that the Southern Ocean essentially responds to changes in the duration of local summer. M.F. Loutre's review of insolation forcing theory helped clarify this difficult subject.

Notably, records were often described in terms of their frequency spectrum. P. Wang emphasized the presence of 400500-kyr oscillations in globally distributed $\delta^{13} \mathrm{C}$ marine records back to the Oligocene, L. Lisiecki analyzed the linear vs non-linear character of the climate's response to obliquity and identified a change in regime around 1.4 Myr (Fig. 1), while D. Verschuren presented evidence for a 11-kyr signal in the recurrence of so-called "African megadroughts". Additionally, P. Pestiaux reminded us that spectral analysis of paleoclimate data facilitates their interpretation in terms of complex system theory.

Finally, on the modeling side, A. Ganoposki presented his "megarun" project, which covers the last 1 Myr of the Pleistocene with the "CLIMBER" model, and A. Abe-Ouchi presented experiments cover- ing several glacial-interglacial cycles, executed with the MIROC general circulation model asynchronously coupled with an ice sheet model.

There was unanimous agreement that the identification of age uncertainties is one of the major hurdles in understanding climate dynamics. J. Hays summarized the CLIMAP and SPECMAP efforts that, more than 15 years ago, delivered synthetic descriptions of leads and lags between the orbital forcing and different aspects of climate's response. The question of whether the time had come for a SPECMAP-2 initiative was debated and it was decided that the answer was probably yes but that our needs had changed. Climate modelers increasingly focus on quantifying model uncertainty. Advanced statistical techniques are being developed to this end but their application requires accessible descriptions of the processes that cause data uncertainty. Thus, there may be a more pressing demand for meta-data (description of the data and how they were produced) than for data sensu stricto.

The symposium, was a true acknowledgment of the friendship that surrounds André Berger, who is now Professor Emeritus at the Catholic University of Louvain. Despite retirement, his commitment to science remains and we are sure to hear of him again.

\section{Acknowledgements}

The meeting was hosted by Université catholique de Louvain, Belgium and sponsored by the Belgian National Fund for Scientific Research, the Belgian Federal Science Policy Office, 
the French Commissariat à I'Energie Atomique, the French Institut National des Sciences de I'Univers, the European Geosciences Union, the Belgian Agency for Radioactive Waste and Enriched Fissile Materials, and the Belgian private company "Vincotte". Early career scientists and scientists from Eastern and developing countries were supported by PAGES and EGU.

\section{References}

Lisiecki, L.E. and Raymo, M.E. 2005: A Pliocene-Pleistocene stack of 57 globally distributed benthic $\delta^{18} 0$ records, Paleoceanography, 20 PA1003, doi:10.1029/2004PA001071
Lisiecki, LE and Raymo, M E 2007: Plio-Pleistocene climate evolution: trends and transitions in glacial cycle dynamics, Quaternary Science Reviews, 26: 56-69.

Laskar, J., Robutel1, P., Joutel1, F., Gastineau, M., Correia, A.C.M. and Levrard B., 2004: A long term numberical solution for the insolation quantities of the Earth, Astronomy and Astrophysics, 428 261-185.

\section{CLIVAR-PAGES-WCRP summer school on El Niño}

\section{Puna, USA, 14-24 June 2008}

\section{Axel Timmermann}

International Pacific Research Center, University of Hawaii, Honolulu; axel@hawaii.edu

The summer school "ENSO Dynamics and Predictability" took place in the lush jungle of Puna on the Big Island of Hawai'i. Sixteen graduate students in oceanography, meteorology and geology from 10 countries gathered to learn from lecturers on a broad range of ENSO-related topics: ENSO theory (Fei-Fei Jin, University of Hawai'i, USA), ENSO phenomenology (Michael McPhaden, NOAA, USA), ENSO predictability (Magdalena Balmaseda, European Centre for Medium-range Weather Forecasts, UK; Richard Kleeman, Courant Institute, USA), and ENSO's sensitivity to past and future climate change (Scott Power, Centre for Australian Weather and Climate Research Bureau of Meteorology/CSIRO, Australia; Axel Timmermann, University of Hawai'i, USA).

Energized by fresh goat milk kefir, exotic local fruit smoothies and island-style cuisine, the students conducted research projects in addition to the 3-4 hour daily lecture-marathon. In teams, they studied the effects of ENSO on the Antarctic Peninsula, the rapid termination of the 2008 La Niña event that was induced by easterly wind bursts, the geographical reaches of a tropical megadrought $4.2 \mathrm{kyr}$ ago, the effects of state-dependent noise on the predictability of ENSO, the dynamics of warm pool El Niño events, the effects of Atlantic multi-decadal SST variability on ENSO, and the role of equatorial waves in the ENSO recharge mechanism. In carrying out these research projects students applied the concepts taught during the lectures, such as the recharge oscillator paradigm, ENSO frequency entrainment, equatorial waves, basin modes, teleconnection patterns and multiplicative noise.

Understanding ENSO's past requires an in-depth understanding of the coupled instability mechanisms that underlie ENSO and the annual cycle in the eastern equatorial Pacific. Oversimplified concepts, such as the dynamical thermostat, can mislead paleo-proxy interpretations, and a thorough heat-budget analysis of corresponding model simulations is usually needed to understand ENSO changes that occurred with past climate forcings, such as orbitally induced variations in solar insolation. Numerous coupled general circulation model studies have demonstrated that for certain ENSO regimes a weaker (stronger) annual cycle corresponds to stronger (weaker) ENSO variability. Testing these model-derived relations with paleo-proxy data, such as corals, lake records, speleothems, mollusks, and tree rings, would be an important contribution towards a better understanding of ENSO forcing mechanisms in the past.

The summer school demonstrated the benefit for climate research of the CLI-
VAR/PAGES Interaction: Climate modelers need paleo-records to validate their models; paleoclimatologists benefit from the dynamical insights provided by climate modeling experiments. An example of a student team project that highlighted this was provided by Intan Nurhati (Georgia Institute of Technology, USA) and Gabriel Bayona (EAFIT University, Columbia). They studied the geographical extent of a 30 - to 50-year-long megadrought that occurred $\sim 4.2 \mathrm{kyr}$ ago and affected the civilizations of Egypt and Mesopotamia. By compiling and synthesizing paleo-data, from archives such as speleothems, lake sediments and ice cores, they derived a map showing the tropical-wide extent of the drought (Fig. 1). To determine what may have caused this drought, they analyzed cosmogenic isotope variations and temperature variability in the N. Atlantic. Results, however, are still inconclusive. Fostering such joint PAGES/CLIVAR activities could become an important legacy of both programs.

\section{Note}

Lectures are available from: http://iprc.soest.hawaii.edu/ axel/ENSOsummerschool.html

\section{Acknowledgements}

The summer school was supported by PAGES, CLIVAR, WCRP, NOAA, the Australian Government (ARCNESS) and the International Pacific Research Center.

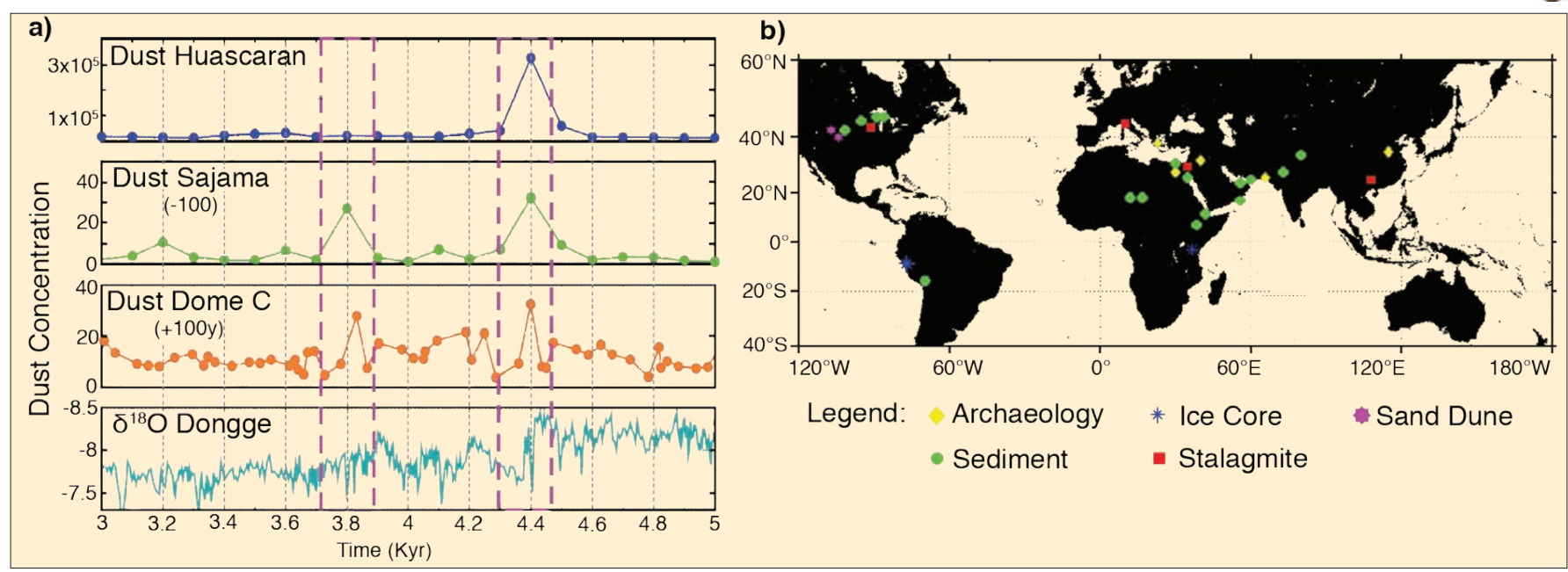

Figure 1:a) Time series of dust fluxes at Huascaran (Peru), Sajama (Bolivia) (timescale shifted by-100 years), EPICA Dome C (Antarctica) (timescale shifted by +100 years) and Dongge Cave $\delta^{18} \mathrm{O}$ (China), indicating major drought periods around the tropics (purple boxes). Dust records indicate that in fact two major droughts occurred around $3.8 \mathrm{kyr}$ and $4.4 \mathrm{kyr}$ BP. In archeological literature, this is often just referred to as the "4.2 kyr event". $\boldsymbol{b}$ ) Extent of the 4.2-kyr-drought event, as derived from different paleo-archives. 